\title{
Anthropometric and Biomechanical Characteristics on Body Segments of Koreans
}

\author{
Se Jin Park ${ }^{1)}$, Chae-Bogk Kim ${ }^{2)}$ and Soo Chan Park ${ }^{1)}$ \\ 1) Ergonomics Research Group, Korea Research Insti tute of Standards and Science \\ 2) Department of Technology Education, Korea National University of Education
}

\begin{abstract}
This paper documents the physical measurements of the Korean population in order to construct a data base for ergonomic design. The dimension, volume, density, mass, and center of mass of Koreans whose ages range from 7 to 49 were investigated. Sixtyfive male subjects and sixty-nine female subjects participated. Eight body segments ( head with neck, trunk, thigh, shank, foot, upper arm, forearm and hand) were directly measured with a Martin-type anthropometer, and the immersion method was adopted to measure the volume of body segments. After this, densities were computed by the density equations in Drillis and Contini (1966). The reaction board method was employed for the measurement of the center of mass. Obtained data were compared with the results in the literature. The results in this paper showed different features on body segment parameters comparing with the results in the literature. The constructed data base can be applied to statistical guideline for product design, workspace design, design of clothing and tools, furniture design and construction of biomechanical models for Korean. Also, they can be extended to the application areas for Mongolian.

(Appl Human Sci, 18 (3): 91-99, 1999)
\end{abstract}

Keywords: body segment, dimension, volume, density, mass, center of mass

\section{Introduction}

Anthoropometric and biomechanical data are important because they can be applied to many practical areas. Since the characteristics of race, sex, and age are important factors for the statistical guideline for product design, workspace design, design of clothing and tools, furniture design, construction of biomechanical models, etc., the physical measurements of the human body are required to describe these characteristics.

In the past, researchers have relied on cadaver-based approach in doing their studies (Dempster, 1955; Clauser et al., 1969; Chandler et al., 1975). Recently, however, researchers began to develop alternative approaches for living subjects instead of cadavers. New technologies including magnetic resonance imaging (MRI) based method (Martin et al., 1989; Mungiole and Martin, 1990), computerized tomography (CT) based method (Ackland et al., 1988; Huang and Suarez, 1983; Huang and Wu, 1976; Rodrigue and Gagnon, 1983), mathematical modeling (Hanavan, 1964), photogrammetry (Kaleps et al., 1984; Jensen, 1978), and gamma mass scanning (Brooks and J acobs, 1975), have been used to overcome the limitations of the cadaver-based approach.

In this study, the immersion method was adopted because it allows for low measurement cost, availability, easy experimental design, and the simple calculation of the density and mass of the human body. Also, there has been very little data to date regarding young males, women, and non-Caucasian in the literature (see Mungiole and Martin, 1990). Therefore, the investigation of the dimension, volume, density and mass of Korean males and females whose ages range from 7 to 49 will present useful data for ergonomic design. The obtained data will be compared with the results by Dempster (1955), and Chandler et al. (1975).

\section{Methods}

\section{Subjects}

In this study, 65 male and 69 female volunteer subjects were recruited from primary schools, secondary schools and companies in Daejon city. An advertisement for recruiting was appeared in a regional newspaper. According to Kim et al. (1997), the distribution of dimensions and weights of population in Daejon city was not much different from that of dimensions and weights of population in Korea. The subjects ranged from age 7 to 49. For each sex, the subjects were divided into 5 groups: primary school students, secondary school students, and those in their twenties, thirties, and forties. There were no significant preference differences between age groups. In Table 1, means and standard deviations of statures and weights of the subjects are presented according to sex and age with sample size. 
Table 1 Statures and weights of subject groups (unit: $\mathrm{cm}$ )

\begin{tabular}{|c|c|c|c|c|c|c|c|}
\hline \multicolumn{2}{|c|}{ Item / Group } & \multicolumn{3}{|c|}{ Male } & \multicolumn{3}{|c|}{ Female } \\
\hline & 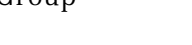 & Mean & S.D & $n$ & Mean & S.D & $n$ \\
\hline \multirow{5}{*}{ Stature } & ( 7-13) yrs. & 144.75 & 9.34 & 14 & 134.83 & 14.13 & 17 \\
\hline & (14-19) yrs. & 168.22 & 7.82 & 13 & 158.53 & 5.28 & 8 \\
\hline & $(20-29)$ yrs. & 172.64 & 5.64 & 18 & 159.94 & 4.78 & 14 \\
\hline & $(30-39)$ yrs. & 170.56 & 4.51 & 13 & 160.93 & 5.13 & 15 \\
\hline & (40- ) yrs. & 166.9 & 4.67 & 7 & 156.19 & 5.55 & 15 \\
\hline \multirow{5}{*}{ Weight $(\mathrm{kg})$} & ( 7-13) yrs. & 39.18 & 10.26 & 14 & 31.29 & 8.36 & 17 \\
\hline & (14-19) yrs. & 58.82 & 6.94 & 13 & 52.86 & 4.41 & 8 \\
\hline & $(20-29)$ yrs. & 68.2 & 8.16 & 18 & 48.99 & 6.38 & 14 \\
\hline & (30-39) yrs. & 68.81 & 6.49 & 13 & 56.44 & 6.48 & 15 \\
\hline & (40- ) yrs. & 67.91 & 4.1 & 7 & 55.78 & 7.13 & 15 \\
\hline
\end{tabular}

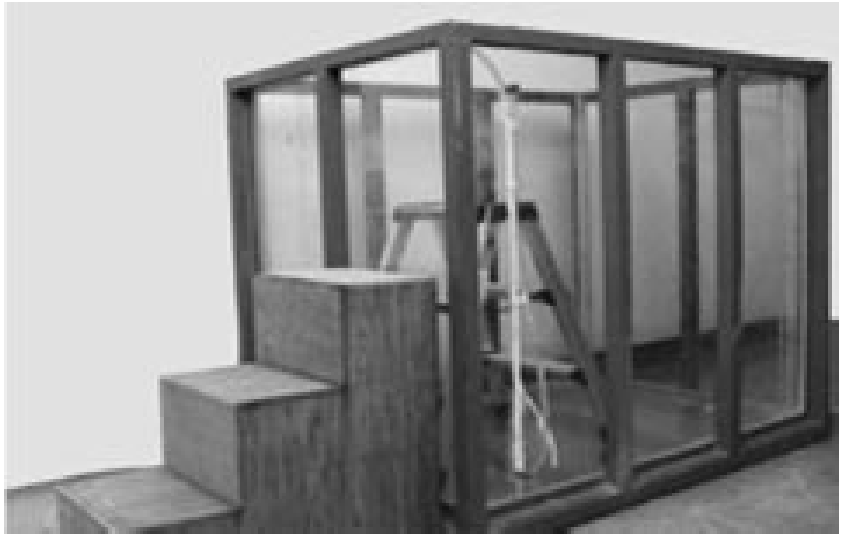

(a)

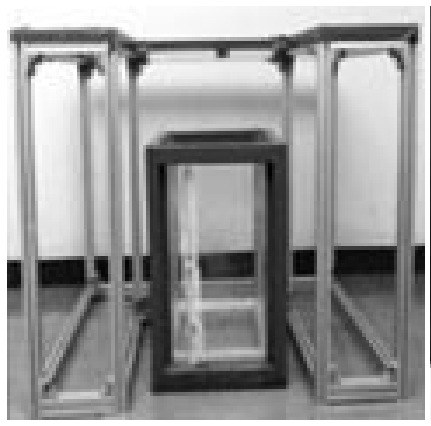

(b)

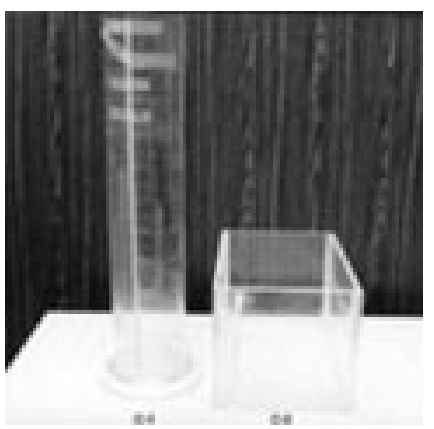

(c)
Fig. 1 Apparatuses for immersion method.

\section{Volume measurement}

Eight body segments (head with neck, trunk, thigh, shank, foot, upper arm, forearm, and hand) were measured. In order to measure the volume of each body segment, the immersion method was employed by using Archimedes's principle. Four types (type I through type IV) of apparatuses were designed (see Fig. 1). The volume of each apparatus was 849750 cc, 77270 cc, $11400 \mathrm{cc}$ and $5000 \mathrm{cc}$, respectively. Figure 2 shows portions of body segments being immersed so that the volume of each body

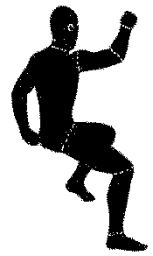

(a)

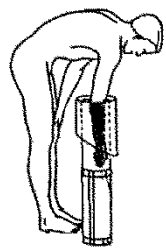

(e)

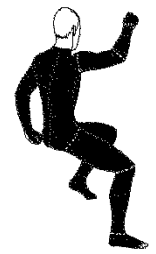

(b)

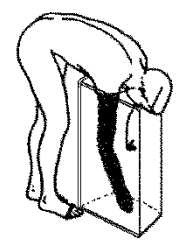

(f)

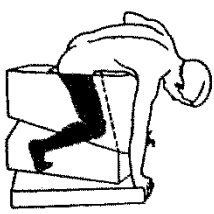

(c)

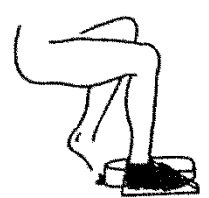

(g)

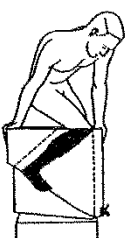

(d)

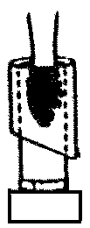

(h)
Fig. 2 Portions of body segments immersed.

segment could be measured.

The procedure of volume measurement was as follows. First, enough water was poured into the apparatus. The volume was checked (there is a $-1 \mathrm{~mm}$ error on reading notch marks). Next, the body segment being measured was immersed in water and the change in the volume was measured. At that time, subject wore swimming suit only. The difference indicates the volume of body segment to measure. Only the right parts of body segments were measured since it was assumed that the bodies were symmetric. Also, BTPS (body temperature and pressure saturated with water vapor) was ignored. Detailed procedure to compute the volume of each body segment is presented in Appendix A.

\section{Density and mass calculation}

The mass of each body segment could not be obtained directly because living subjects participated in this study. According to Drillis and Contini (1966), there is a method to calculate the densities of body segments using the 


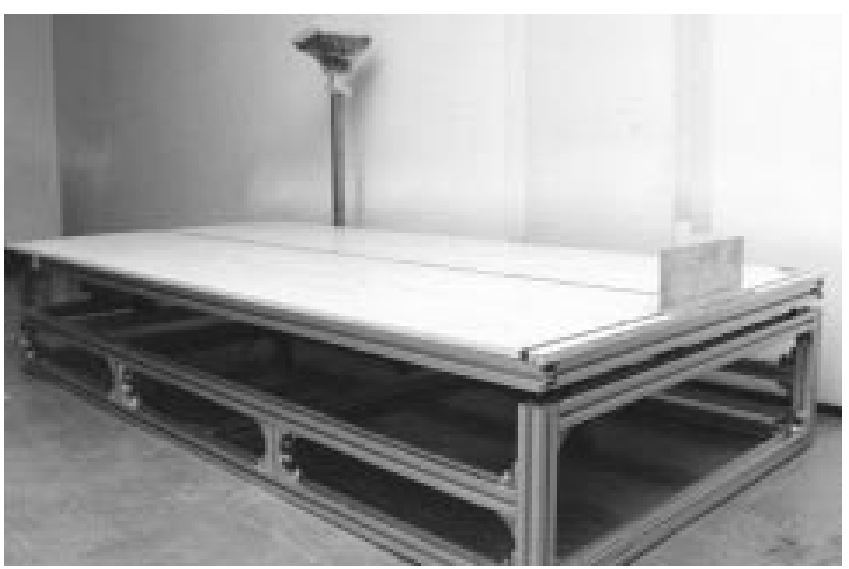

Fig. 3 Designed reaction board.

density of of whole body. They presented linear regression equations between whole body density and each body segment density. In this study, these linear regression equations were used to compute the density of each body segment since Lim et al. (1993) reported that there was no significant difference (less than $2 \mathrm{~kg}$ ) between actual body weight and estimated body weight even though the equations by Drillis and Contini (1966) were employed.

In order to obtain the mass of each body segment, the density of each body segment was multiplied by the volume of the corresponding body segment obtained by the immersion method.

\section{Center of mass measurement}

For the measurement of the center of mass, the reaction board method was employed since it allows to check the reaction change. The reaction board consisted of a rigid board mounted on a scale at one end and a pivot point at the other end. Figure 3 represents the designed reaction board.

Five types of postures on the reaction board were developed to measure the center of mass. Figure 4 shows postures on the reaction board. Each posture from Fig. 4 (a) to Fig. 4 (e) was designed for the center of mass of the whole body, forearm with hand, upper arm and forearm with hand, shank with foot, and thigh and shank with foot, respectively.

As mentioned earlier, since living subjects were used in this study, it is difficult to obtain the exact center of mass of each body segment. Instead of obtaining the center of mass on each body segment, the centers of masses on five body segment combinations were investigated. In order to arrive at an accurate estimation, the procedure in Winter (1979) was used for the calculation of the center of mass. Great attention was given on the exact postures of the subjects for obtaining precise data.

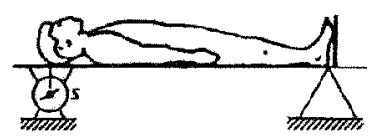

(a)

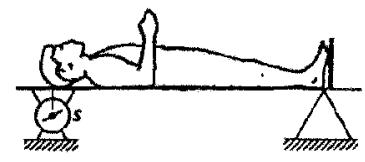

(b)

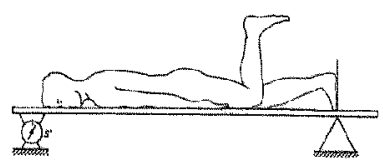

(d)

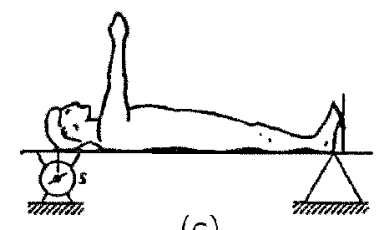

(c)

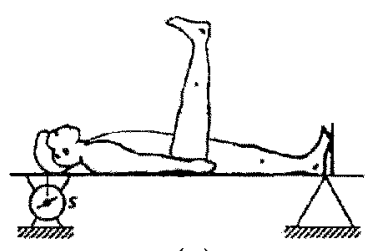

(e)
Fig. 4 Postures on reaction board.

\section{Results}

Eight body segments were directly measured with a Martin-type anthropometer. For the definition of body segments, see Dempster (1955) and Clauser et al. (1969). Means and standard deviations of anthropometric measurements for the subjects are shown in Appendix B ( Table B1). Figure 5 represents linear regression models and correlation coefficients between weight and the volume of the whole body in each group.

The mean volumes of body segments according to age and sex are shown in Appendix B (Table B2). Also, the densities of body segments according to sex and age are presented in Appendix B (Table B3). The obtained density results were compared with Dempster (1955), and Chandler et al. (1975). Both the densities of right and left body segments in Dempster (1955) were averaged.

Given their densities and volumes, the masses of body segments can be obtained. The masses of particular body segments are shown in Appendix B (Table B4). Mass differences between whole body and actual weight imply that some estimation errors on masses of body segments existed. In order to validate the proposed method, we employ t-test in terms of real weights and estimated weights of subjects according to age and sex. Table 3 shows the test results of mean differences between real weights and estimated weights.

Mass proportions of each body segment represented as a percentage of the weight of the whole body are shown in Appendix B (Table B5). The obtained centers of masses of particular body segments are presented in Appendix $B$ (Table B6). The values in Table B6 denote percentage from proximal end. 

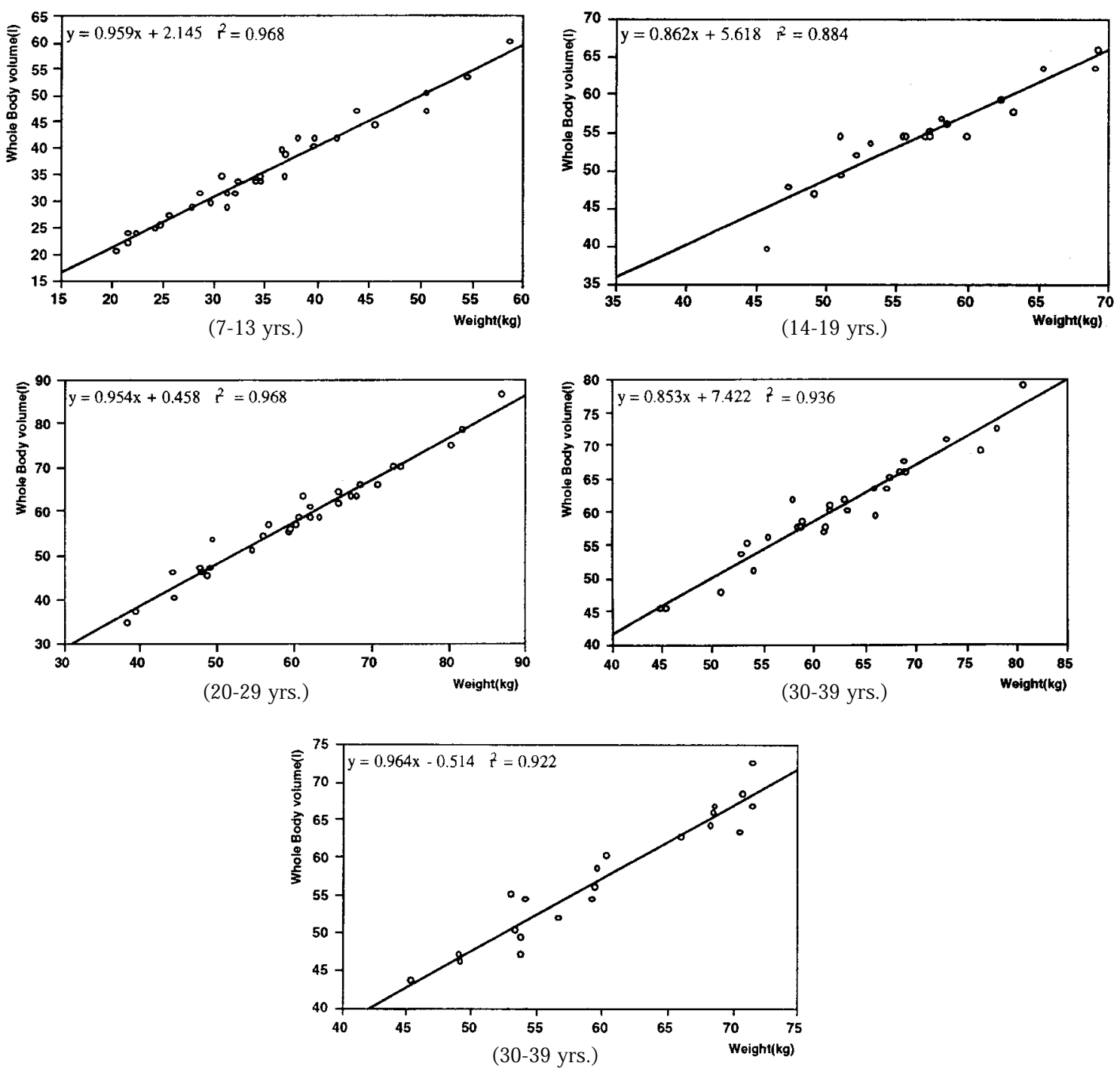

Fig. 5 Linear regression models between weight and volume.

Table 2 Comparisons of body segments densities (unit: $\mathrm{kg} / \mathrm{l}$ )

\begin{tabular}{lccc}
\hline Body Segment & Dempster & Chandler et al. & Park et al. \\
\hline Upper arm & 1.070 & 0.997 & 1.049 \\
Forearm & 1.125 & 1.043 & 1.115 \\
Hand & 1.155 & 1.079 & 1.129 \\
Thigh & 1.050 & 1.018 & 1.047 \\
Shank & 1.090 & 1.059 & 1.081 \\
Foot & 1.095 & 1.073 & 1.088 \\
\hline
\end{tabular}

\section{Discussion}

In dimension measurements, as expected, the results were quite different from studies in which Caucasians were the subjects (see Table B1). These results were compatible with the article presented by Nakanishi and
Nethery (1999)

According to Fig. 5, volume and weight are highly correlated. However, designers needs to note the subjects between 14 and 19 because there are several subjects who have large deviation from the values by regression equation comparing with other groups.

There are noticeable factors in the results of volume measurements (see Table B2). The mean weights and volumes of male subjects between 20 and 49 are almost the same. However, for subjects in their twenties, the volumes of thigh and foot are more than other groups. The subjects in their thirties have more volume on head with neck and less on shank comparing with other groups. The volume of the forearm segment decreases as age increases.

The mean weight and whole body volume of female subjects in their twenties are less than those of other female adult subjects. The volumes of head with neck, 
Table 3 Tests of equality of means between real and estimated weights

\begin{tabular}{lrcccc}
\hline \multicolumn{1}{c}{ group } & $\mathrm{n}$ & real weight & estimated weight & difference & $\mathrm{P}$ \\
\hline all & 134 & $53.9903-14.3134$ & $53.9136-14.0493$ & 0.0707 & 0.967 \\
male & 65 & $60.1646-13.9361$ & $59.9928-13.7346$ & 0.1718 & 0.944 \\
female & 69 & $48.1739-12.1305$ & $48.1986-11.8340$ & 0.0246 & 0.990 \\
$7-13$ (all) & 31 & $34.8548-9.9430$ & $35.1823-9.7075$ & 0.3274 & 0.896 \\
$7-13 \quad$ (male) & 14 & $39.1786-10.2625$ & $39.3486-10.1482$ & 0.1700 & 0.965 \\
$7-13$ (female) & 17 & $31.2941-8.3648$ & $31.7512-8.0821$ & 0.4571 & 0.872 \\
$14-19$ (all) & 21 & $56.5524-6.6714$ & $56.4024-6.6860$ & 0.1500 & 0.942 \\
$14-19$ (male) & 13 & $58.8231-6.9404$ & $58.7015-6.9222$ & 0.1215 & 0.965 \\
$14-19$ (female) & 8 & $52.8625-4.4107$ & $52.6663-4.4504$ & 0.1962 & 0.931 \\
$20-29$ (all) & 32 & $59.7938-12.1413$ & $59.6994-11.9812$ & 0.0944 & 0.975 \\
$20-29$ (male) & 18 & $68.2000-8.1635$ & $67.9906-8.0405$ & 0.2094 & 0.939 \\
$20-29$ (female) & 14 & $48.9857-6.3817$ & $49.0393-6.3409$ & 0.0536 & 0.982 \\
$30-39$ (all) & 28 & $62.1821-8.9434$ & $61.8032-8.8637$ & 0.3789 & 0.874 \\
$30-39$ (male) & 13 & $68.8077-6.4924$ & $68.3277-6.4715$ & 0.4800 & 0.852 \\
$30-39$ (female) & 15 & $56.4400-6.4837$ & $56.1487-6.4680$ & 0.2913 & 0.903 \\
$40-\quad$ (all) & 22 & $59.6409-8.4923$ & $59.5118-8.3066$ & 0.1291 & 0.960 \\
$40-\quad$ (male) & 7 & $67.9143-4.1010$ & $67.6343-4.2051$ & 0.2800 & 0.902 \\
$40-\quad$ (female) & 15 & $55.7800-7.1256$ & $55.7213-6.8950$ & 0.0587 & 0.982 \\
\hline
\end{tabular}

Mean - SD.

trunk, foot, forearm, and hand of subjects in their twenties are less than other adult groups. However, it is interesting to note that the volume of shank is the most compared with any other group, and the volume of upper arm is the most except for one group (subjects in their thirties).

The densities of body segments of subjects in primary schools (age from 7 to 13) are less than those of other groups as showed in Table B3. It is noticeable that there are much density differences between male subjects whose ages are greater than 13. For female subjects, there is a trend that density increases until age 19 and then decreases. However, density increases again when the ages of female subjects are greater than forty. According to obtained results, body segments can be divided into three groups based on density. The densities of forearm and hand are above average. However, the densities of thigh, upper arm and shank are below average.

According to Table 2, the obtained density results are between the results of Dempster (1955), and Chandler et al. (1975). In order to obtain more precise densities of body segments, CT or MRI based approaches will be needed even though they require expensive equipment and high costs.

Based on the results in Table 3, it is concluded that real weights and estimated weights of subjects were not significantly different. There were not many errors on the estimation of the mass of each body segment and the obtained results can be supported by Lim et al. (1993). Before testing equality of means, Levene's test was adopted to check the equality of variance. In all cases, equal variances were assumed based on the test results.

According to the results in Table B4, subjects in the primary school have significiently less mass than any other groups on all body segments. However, from age 14 to age 49 , there are not many mass differences between groups. Generally, male subjects have higher mass proportions of body segments than those of female subjects. However, the mass proportions of thigh for female subject groups are greater than those for male subject groups (see Table B5).

For the body segments of thigh and shank with foot, and shank with foot, female subjects in primary school have higher percentages from proximal end than male subjects in primary school (see Table B6). For any other body segments, male subjects had higher percentages from proximal end than female subjects. It is interesting to note that the subjects in their forties, primary school and secondary school students have greater percentages from proximal end than other subjects.

\section{Conclusion}

This paper presented dimensions, volumes, densities, masses and centers of body segments of Koreans according to sex and age. The one hundred twenty five participating subjects were divided into ten groups, the groups being based on sex and age.

Eight body segments were directly measured with Martin-type anthropometer and the immersion method was adopted to measure the volume of body segments. Following this, densities were computed using the density equations in Drillis and Contini (1966). For the measurement of center of mass, the reaction board method was employed. Obtained results showed different features on body segment parameters comparing with the results in the literature. 


\section{Appendix A. Volume measurement procedure}

1. Whole body volume

(1) Record initial water level (a) of type I apparatus.

(2) Immerse the whole body to water ( see Fig. 2 (a)).

(3) Record changed water level (b).

(4) Whole body volume $=(b-a) \cdot$ (the base area of apparatus)

2. F oot volume

(1) Record initial water level (a) of type III apparatus.

(2) Immerse foot to water (see Fig. 2 (g)).

(3) Record changed water level (b).

(4) F oot volume $=(b-a) \cdot($ the base area of apparatus)

3. Shank volume

(1) Record initial water level (a) of type II apparatus.

(2) Immerse shank and foot to water (see Fig. 2 (d)).

(3) Record changed water level (b).

(4) Shank volume $=\{(b-a) \cdot$ (the base area of apparatus) $\}$ - (foot volume)

4. Thigh volume

(1) Record initial water level (a) of type II apparatus.

(2) Immerse thigh, shank and foot to water (see Fig. 2 (c)).

(3) Record changed water level (b).

(4) Thigh volume $=\{(b-a) \cdot$ (the base area of apparatus) \} - (shank volume) - (foot volume)
5. Hand volume

(1) Record initial water level (a) of type IV apparatus.

(2) Immerse hand to water (see Fig. 2 (h)).

(3) Record changed water level (b).

(4) Hand volume $=(b-a) \cdot$ (the base area of apparatus)

6. Forearm volume

(1) Record initial water level (a) of type IV apparatus.

(2) Immerse upperarm, forearm and hand to water (see Fig. 2 ( $f)$ ).

(3) Record changed water level (b).

(4) Forearm volume $=(b-a) \cdot$ (the base area of apparatus) - (hand volume)

7. Upper arm volume

(1) Record initial water level (a) of type II apparatus.

(2) Immerse forearm and hand to water (see Fig. 2 (e)).

(3) Record changed water level (b).

(4) Upper arm volume $=(b-a) \cdot$ (the base area of apparatus) - (forearm volume) - (hand volume)

\section{Trunk volume}

(1) Record initial water level (a) of type I apparatus.

(2) Immerse forearm and hand to water (see Fig. 2 (b)).

(3) Record changed water level (b).

(4) Trunk volume $=(b-a) \cdot($ the base area of apparatus) - 2 . (thigh volume + shank volume + foot volume + upper arm volume + forearm volume + hand volume)

\section{Appendix B. Data sets of Korean population}

Table B1 Anthropometric measures of body segments

(unit: $\mathrm{cm}$ )

\begin{tabular}{|c|c|c|c|c|c|c|c|}
\hline \multirow{2}{*}{\multicolumn{2}{|c|}{ Item / Group }} & \multicolumn{3}{|c|}{ Male } & \multicolumn{3}{|c|}{ Female } \\
\hline & & Mean & S.D & $n$ & Mean & S.D & $n$ \\
\hline \multirow{5}{*}{ Cervical height } & ( 7-13) yrs. & 121.74 & 9.18 & 14 & 112.67 & 12.29 & 17 \\
\hline & (14-19) yrs. & 142.68 & 7.0 & 13 & 134.39 & 4.67 & 8 \\
\hline & (20-29) yrs. & 145.23 & 5.2 & 18 & 135.26 & 4.17 & 14 \\
\hline & (30-39) yrs. & 144.42 & 4.29 & 13 & 135.88 & 4.5 & 15 \\
\hline & (40- ) yrs. & 141.49 & 4.57 & 7 & 131.81 & 5.15 & 15 \\
\hline \multirow{5}{*}{ Trochanter height } & ( 7-13) yrs. & 72.36 & 6.14 & 14 & 66.88 & 7.63 & 17 \\
\hline & (14-19) yrs. & 81.9 & 6.14 & 13 & 77.84 & 2.78 & 8 \\
\hline & (20-29) yrs. & 82.94 & 3.53 & 18 & 77.24 & 2.8 & 14 \\
\hline & (30-39) yrs. & 81.14 & 3.67 & 13 & 76.35 & 3.53 & 15 \\
\hline & $(40-)$ yrs. & 78.7 & 2.87 & 7 & 74.25 & 3.58 & 15 \\
\hline \multirow{5}{*}{$\begin{array}{l}\text { Lateral femoral } \\
\text { epicondyle height }\end{array}$} & ( 7-13) yrs. & 40.8 & 4.07 & 14 & 35.69 & 4.92 & 17 \\
\hline & (14-19) yrs. & 44.95 & 2.7 & 13 & 41.73 & 2.62 & 8 \\
\hline & (20-29) yrs. & 44.29 & 2.16 & 18 & 42.03 & 2.66 & 14 \\
\hline & $(30-39)$ yrs. & 45.19 & 2.65 & 13 & 40.35 & 2.71 & 15 \\
\hline & $(40-\quad)$ yrs. & 43.5 & 2.77 & 7 & 39.46 & 1.51 & 15 \\
\hline \multirow{5}{*}{$\begin{array}{l}\text { Acromion to } \\
\text { olecranon length }\end{array}$} & ( 7-13) yrs. & 26.5 & 1.99 & 14 & 24.8 & 2.72 & 17 \\
\hline & (14-19) yrs. & 30.3 & 1.1 & 13 & 29.96 & 1.45 & 8 \\
\hline & $(20-29)$ yrs. & 42.87 & 1.83 & 18 & 38.94 & 2.2 & 14 \\
\hline & $(30-39)$ yrs. & 41.46 & 2.06 & 13 & 40.07 & 1.86 & 15 \\
\hline & $(40-\quad)$ yrs. & 42.11 & 3.88 & 7 & 39.5 & 1.5 & 15 \\
\hline \multirow{5}{*}{$\begin{array}{l}\text { Olecranon to } \\
\text { fingertip length }\end{array}$} & ( 7-13) yrs. & 36.86 & 2.81 & 14 & 33.9 & 2.82 & 17 \\
\hline & $(14-19)$ yrs. & 42.38 & 2.69 & 13 & 40.28 & 1.71 & 8 \\
\hline & $(20-29)$ yrs. & 42.87 & 1.83 & 18 & 38.94 & 2.2 & 14 \\
\hline & $(30-39)$ yrs. & 41.46 & 2.06 & 13 & 40.07 & 1.86 & 15 \\
\hline & $(40-\quad)$ yrs. & 42.11 & 3.88 & 7 & 39.5 & 1.5 & 15 \\
\hline \multirow{5}{*}{$\begin{array}{l}\text { Acromion to } \\
\text { fingertip length }\end{array}$} & ( 7-13) yrs. & 63.36 & 4.56 & 14 & 58.78 & 5.27 & 17 \\
\hline & (14-19) yrs. & 72.68 & 3.29 & 13 & 70.24 & 2.7 & 8 \\
\hline & $(20-29)$ yrs. & 72.47 & 2.8 & 18 & 67.99 & 2.75 & 14 \\
\hline & $(30-39)$ yrs. & 72.47 & 2.8 & 13 & 68.97 & 2.87 & 15 \\
\hline & $(40-\quad)$ yrs. & 71.76 & 4.39 & 7 & 67.71 & 2.87 & 15 \\
\hline
\end{tabular}


Table B 2 Volumes of body segments

(unit: I)

\begin{tabular}{|c|c|c|c|c|c|}
\hline \multicolumn{2}{|c|}{ Segment / Group } & \multicolumn{2}{|c|}{ Male } & \multicolumn{2}{|c|}{ Female } \\
\hline & & mean & S.D & mean & S.D \\
\hline \multirow{5}{*}{ Wholebody } & ( 7-13) yrs. & 39.48 & 10.31 & 32.37 & 8.10 \\
\hline & (14-19) yrs. & 56.23 & 5.77 & 51.36 & 5.75 \\
\hline & (20-29) yrs. & 65.04 & 8.39 & 47.85 & 7.73 \\
\hline & (30-39) yrs. & 65.75 & 5.99 & 55.83 & 6.33 \\
\hline & (40-49) yrs. & 64.7 & 3.36 & 53.80 & 7.64 \\
\hline \multirow{5}{*}{ Head + Neck } & $(7-13)$ yrs. & 4.77 & 0.98 & 4.59 & 1.88 \\
\hline & (14-19) yrs. & 5.39 & 1.41 & 5.26 & 1.52 \\
\hline & (20-29) yrs. & 5.45 & 1.21 & 4.66 & 1.05 \\
\hline & $(30-39)$ yrs. & 6.16 & 1.45 & 5.54 & 1.27 \\
\hline & $(40-49)$ yrs. & 5.66 & 1.99 & 5.43 & 1.34 \\
\hline \multirow{5}{*}{ Trunk } & ( 7-13) yrs. & 18.94 & 5.24 & 15.24 & 4.18 \\
\hline & (14-19) yrs. & 26.55 & 2.81 & 24.52 & 5.26 \\
\hline & (20-29) yrs. & 32.08 & 4.94 & 22.52 & 4.41 \\
\hline & $(30-39)$ yrs. & 34.83 & 3.61 & 27.60 & 3.42 \\
\hline & $(40-49)$ yrs. & 34.07 & 3.36 & 28.36 & 4.97 \\
\hline \multirow{5}{*}{ Thigh } & ( 7-13) yrs. & 3.96 & 1.76 & 3.57 & 1.18 \\
\hline & (14-19) yrs. & 5.83 & 1.21 & 5.79 & 0.91 \\
\hline & $(20-29)$ yrs. & 6.69 & 1.41 & 5.37 & 1.20 \\
\hline & $(30-39)$ yrs. & 6.17 & 1.10 & 6.08 & 1.21 \\
\hline & $(40-49)$ yrs. & 6.12 & 1.09 & 5.51 & 1.00 \\
\hline \multirow{5}{*}{ Shank } & ( 7-13) yrs. & 1.59 & 0.41 & 1.40 & 0.50 \\
\hline & (14-19) yrs. & 2.66 & 0.39 & 2.24 & 0.20 \\
\hline & $(20-29)$ yrs. & 2.69 & 0.60 & 2.31 & 0.47 \\
\hline & $(30-39)$ yrs. & 2.42 & 0.45 & 2.22 & 0.46 \\
\hline & $(40-49)$ yrs. & 2.82 & 0.86 & 1.94 & 0.45 \\
\hline \multirow{5}{*}{ Foot } & ( 7-13) yrs. & 0.72 & 0.17 & 0.64 & 0.11 \\
\hline & (14-19) yrs. & 0.89 & 0.09 & 0.74 & 0.08 \\
\hline & $(20-29)$ yrs. & 0.93 & 0.12 & 0.70 & 0.16 \\
\hline & $(30-39)$ yrs. & 0.97 & 0.12 & 0.72 & 0.11 \\
\hline & $(40-49)$ yrs. & 0.87 & 0.08 & 0.72 & 0.16 \\
\hline \multirow{5}{*}{ Upper arm } & ( 7-13) yrs. & 0.84 & 0.23 & 0.75 & 0.30 \\
\hline & (14-19) yrs. & 1.48 & 0.35 & 1.13 & 0.22 \\
\hline & $(20-29)$ yrs. & 1.78 & 0.41 & 1.25 & 0.42 \\
\hline & $(30-39)$ yrs. & 1.54 & 0.37 & 1.28 & 0.39 \\
\hline & (40-49) yrs. & 1.39 & 0.30 & 1.06 & 0.29 \\
\hline \multirow{5}{*}{ Forearm } & ( 7-13) yrs. & 0.55 & 0.15 & 0.42 & 0.11 \\
\hline & (14-19) yrs. & 0.83 & 0.09 & 0.68 & 0.11 \\
\hline & $(20-29)$ yrs. & 0.92 & 0.12 & 0.61 & 0.12 \\
\hline & $(30-39)$ yrs. & 0.90 & 0.13 & 0.71 & 0.11 \\
\hline & $(40-49)$ yrs. & 0.90 & 0.09 & 0.68 & 0.11 \\
\hline \multirow{5}{*}{ Hand } & ( 7-13) yrs. & 0.24 & 0.05 & 0.19 & 0.04 \\
\hline & (14-19) yrs. & 0.36 & 0.05 & 0.30 & 0.03 \\
\hline & $(20-29)$ yrs. & 0.37 & 0.04 & 0.26 & 0.04 \\
\hline & $(30-39)$ yrs. & 0.38 & 0.03 & 0.29 & 0.05 \\
\hline & (40-49) yrs. & 0.38 & 0.03 & 0.31 & 0.05 \\
\hline
\end{tabular}

Table B3 Densities of body segments (unit: kg/l)

\begin{tabular}{|c|c|c|c|c|c|}
\hline \multirow{2}{*}{\multicolumn{2}{|c|}{ Segment / Group }} & \multicolumn{2}{|c|}{ Male } & \multicolumn{2}{|c|}{ Female } \\
\hline & & mean & S.D & mean & S.D \\
\hline \multirow{5}{*}{ Wholebody } & ( 7-13) yrs. & 0.993 & 0.037 & 0.965 & 0.055 \\
\hline & (14-19) yrs. & 1.045 & 0.034 & 1.034 & 0.062 \\
\hline & (20-29) yrs. & 1.050 & 0.021 & 1.03 & 0.055 \\
\hline & (30-39) yrs. & 1.047 & 0.032 & 1.011 & 0.038 \\
\hline & $(40-49)$ yrs. & 1.050 & 0.032 & 1.048 & 0.049 \\
\hline \multirow{5}{*}{ Thigh } & ( 7-13) yrs. & 1.008 & 0.026 & 0.987 & 0.033 \\
\hline & (14-19) yrs. & 1.044 & 0.024 & 1.036 & 0.043 \\
\hline & (20-29) yrs. & 1.047 & 0.015 & 1.033 & 0.038 \\
\hline & (30-39) yrs. & 1.045 & 0.022 & 1.021 & 0.026 \\
\hline & (40-49) yrs. & 1.047 & 0.022 & 1.046 & 0.034 \\
\hline \multirow{5}{*}{ Shank } & ( 7-13) yrs. & 1.036 & 0.029 & 1.011 & 0.038 \\
\hline & (14-19) yrs. & 1.077 & 0.026 & 1.068 & 0.049 \\
\hline & (20-29) yrs. & 1.081 & 0.017 & 1.060 & 0.041 \\
\hline & $(30-39)$ yrs. & 1.078 & 0.025 & 1.054 & 0.032 \\
\hline & $(40-49)$ yrs. & 1.081 & 0.025 & 1.079 & 0.039 \\
\hline \multirow{5}{*}{ Foot } & ( 7-13) yrs. & 1.044 & 0.029 & 1.023 & 0.042 \\
\hline & (14-19) yrs. & 1.085 & 0.026 & 1.076 & 0.048 \\
\hline & (20-29) yrs. & 1.088 & 0.017 & 1.068 & 0.040 \\
\hline & (30-39) yrs. & 1.086 & 0.024 & 1.060 & 0.031 \\
\hline & (40-49) yrs. & 1.088 & 0.024 & 1.095 & 0.033 \\
\hline \multirow{5}{*}{ Upper arm } & ( 7-13) yrs. & 1.000 & 0.032 & 0.980 & 0.046 \\
\hline & (14-19) yrs. & 1.045 & 0.029 & 1.035 & 0.057 \\
\hline & $(20-29)$ yrs. & 1.049 & 0.018 & 1.029 & 0.048 \\
\hline & $(30-39)$ yrs. & 1.047 & 0.027 & 1.016 & 0.032 \\
\hline & (40-49) yrs. & 1.049 & 0.027 & 1.048 & 0.042 \\
\hline \multirow{5}{*}{ Forearm } & ( 7-13) yrs. & 1.041 & 0.048 & 1.005 & 0.071 \\
\hline & (14-19) yrs. & 1.109 & 0.044 & 1.095 & 0.080 \\
\hline & (20-29) yrs. & 1.115 & 0.028 & 1.089 & 0.071 \\
\hline & $(30-39)$ yrs. & 1.111 & 0.041 & 1.065 & 0.049 \\
\hline & (40-49) yrs. & 1.115 & 0.041 & 1.113 & 0.064 \\
\hline \multirow{5}{*}{ Hand } & ( 7-13) yrs. & 1.030 & 0.065 & 0.981 & 0.095 \\
\hline & (14-19) yrs. & 1.120 & 0.058 & 1.101 & 0.107 \\
\hline & $(20-29)$ yrs. & 1.129 & 0.037 & 1.094 & 0.095 \\
\hline & $(30-39)$ yrs. & 1.123 & 0.055 & 1.062 & 0.065 \\
\hline & $(40-49)$ yrs. & 1.128 & 0.055 & 1.126 & 0.086 \\
\hline
\end{tabular}


Table B 4 Masses of body segments

(unit: $\mathrm{kg}$ )

\begin{tabular}{|c|c|c|c|c|c|}
\hline \multirow{2}{*}{\multicolumn{2}{|c|}{ Segment / Group }} & \multicolumn{2}{|c|}{ Male } & \multicolumn{2}{|c|}{ Female } \\
\hline & & mean & S.D & mean & S.D \\
\hline \multirow{5}{*}{ Weight } & ( 7-13) yrs. & 39.18 & 10.26 & 31.29 & 8.36 \\
\hline & (14-19) yrs. & 58.82 & 6.94 & 52.81 & 4.41 \\
\hline & $(20-29)$ yrs. & 68.20 & 8.16 & 48.99 & 6.38 \\
\hline & $(30-39)$ yrs. & 68.81 & 6.49 & 56.44 & 6.48 \\
\hline & $(40-49)$ yrs. & 67.91 & 4.10 & 56.21 & 7.19 \\
\hline \multirow{5}{*}{ Wholebody } & ( 7-13) yrs. & 40.88 & 10.57 & 35.17 & 8.77 \\
\hline & (14-19) yrs. & 58.87 & 6.52 & 53.15 & 5.44 \\
\hline & $(20-29)$ yrs. & 66.77 & 7.70 & 51.13 & 6.97 \\
\hline & $(30-39)$ yrs. & 69.01 & 6.28 & 58.99 & 6.35 \\
\hline & $(40-49)$ yrs. & 67.99 & 3.64 & 56.41 & 8.53 \\
\hline \multirow{5}{*}{ Thigh } & $(7-13)$ yrs. & 3.99 & 1.78 & 3.52 & 1.19 \\
\hline & (14-19) yrs. & 6.10 & 1.36 & 5.99 & 0.89 \\
\hline & $(20-29)$ yrs. & 6.99 & 1.41 & 5.52 & 1.12 \\
\hline & $(30-39)$ yrs. & 6.45 & 1.18 & 6.22 & 1.29 \\
\hline & $(40-49)$ yrs. & 6.42 & 1.19 & 5.73 & 1.09 \\
\hline \multirow{5}{*}{ Shank } & ( 7-13) yrs. & 1.65 & 0.44 & 1.42 & 0.54 \\
\hline & (14-19) yrs. & 2.87 & 0.44 & 2.39 & 0.22 \\
\hline & (20-29) yrs. & 2.90 & 0.65 & 2.44 & 0.47 \\
\hline & $(30-39)$ yrs. & 2.61 & 0.48 & 2.33 & 0.49 \\
\hline & $(40-49)$ yrs. & 3.05 & 0.92 & 2.11 & 0.47 \\
\hline \multirow{5}{*}{ Foot } & ( 7-13) yrs. & 0.75 & 0.18 & 0.65 & 0.13 \\
\hline & (14-19) yrs. & 0.96 & 0.11 & 0.79 & 0.08 \\
\hline & $(20-29)$ yrs. & 1.01 & 0.13 & 0.74 & 0.16 \\
\hline & $(30-39)$ yrs. & 1.05 & 0.14 & 0.76 & 0.12 \\
\hline & $(40-49)$ yrs. & 0.94 & 0.09 & 0.78 & 0.16 \\
\hline \multirow{5}{*}{ Upper arm } & ( 7-13) yrs. & 0.84 & 0.23 & 0.74 & 0.32 \\
\hline & (14-19) yrs. & 1.56 & 0.39 & 1.17 & 0.21 \\
\hline & $(20-29)$ yrs. & 1.87 & 0.43 & 1.27 & 0.38 \\
\hline & $(30-39)$ yrs. & 1.61 & 0.38 & 1.29 & 0.38 \\
\hline & $(40-49)$ yrs. & 1.47 & 0.34 & 1.11 & 0.29 \\
\hline \multirow{5}{*}{ Forearm } & ( 7-13) yrs. & 0.57 & 0.16 & 0.43 & 0.12 \\
\hline & (14-19) yrs. & 0.93 & 0.12 & 0.74 & 0.1 \\
\hline & $(20-29)$ yrs. & 1.03 & 0.14 & 0.66 & 0.11 \\
\hline & $(30-39)$ yrs. & 0.99 & 0.17 & 0.76 & 0.12 \\
\hline & $(40-49)$ yrs. & 1.01 & 0.12 & 0.76 & 0.12 \\
\hline \multirow{5}{*}{ Hand } & ( 7-13) yrs. & 0.25 & 0.05 & 0.19 & 0.05 \\
\hline & (14-19) yrs. & 0.40 & 0.06 & 0.33 & 0.04 \\
\hline & $(20-29)$ yrs. & 0.42 & 0.05 & 0.29 & 0.05 \\
\hline & $(30-39)$ yrs. & 0.43 & 0.04 & 0.31 & 0.05 \\
\hline & $(40-49)$ yrs. & 0.43 & 0.05 & 0.35 & 0.06 \\
\hline
\end{tabular}

Table B 5 Mass proportions of body segments (unit: \%)

\begin{tabular}{|c|c|c|c|c|c|}
\hline \multicolumn{2}{|c|}{ Segment / Group } & \multicolumn{2}{|c|}{ Male } & \multicolumn{2}{|c|}{ F emale } \\
\hline segाना & T & mean & S.D & mean & S.D \\
\hline \multirow{5}{*}{ Thigh } & ( 7-13) yrs. & 9.87 & 1.99 & 10.77 & 2.16 \\
\hline & (14-19) yrs. & 10.32 & 1.36 & 11.39 & 1.93 \\
\hline & $(20-29)$ yrs. & 10.48 & 1.58 & 11.25 & 1.76 \\
\hline & $(30-39)$ yrs. & 9.33 & 1.12 & 10.95 & 1.42 \\
\hline & (40-49) yrs. & 9.48 & 1.86 & 10.25 & 1.92 \\
\hline \multirow{5}{*}{ Shank } & ( 7-13) yrs. & 4.26 & 0.77 & 4.37 & 1.11 \\
\hline & (14-19) yrs. & 4.89 & 0.53 & 4.54 & 0.44 \\
\hline & (20-29) yrs. & 4.25 & 0.74 & 4.89 & 0.78 \\
\hline & $(30-39)$ yrs. & 3.81 & 0.67 & 4.08 & 0.83 \\
\hline & $(40-49)$ yrs. & 4.47 & 1.21 & 3.74 & 0.57 \\
\hline \multirow{5}{*}{ Foot } & ( 7-13) yrs. & 1.96 & 0.35 & 2.16 & 0.40 \\
\hline & (14-19) yrs. & 1.64 & 0.16 & 1.50 & 0.19 \\
\hline & (20-29) yrs. & 1.49 & 0.19 & 1.49 & 0.27 \\
\hline & (30-39) yrs. & 1.54 & 0.23 & 1.34 & 0.16 \\
\hline & $(40-49)$ yrs. & 1.39 & 0.13 & 1.39 & 0.23 \\
\hline \multirow{5}{*}{ Upper arm } & ( 7-13) yrs. & 2.07 & 0.42 & 2.33 & 0.78 \\
\hline & (14-19) yrs. & 2.62 & 0.43 & 2.25 & 0.45 \\
\hline & $(20-29)$ yrs. & 2.73 & 0.49 & 2.57 & 0.55 \\
\hline & (30-39) yrs. & 2.33 & 0.41 & 2.28 & 0.53 \\
\hline & $(40-49)$ yrs. & 2.15 & 0.44 & 1.96 & 0.37 \\
\hline \multirow{5}{*}{ Forearm } & ( 7-13) yrs. & 1.45 & 0.12 & 1.37 & 0.10 \\
\hline & (14-19) yrs. & 1.58 & 0.13 & 1.39 & 0.12 \\
\hline & $(20-29)$ yrs. & 1.51 & 0.17 & 1.34 & 0.12 \\
\hline & $(30-39)$ yrs. & 1.45 & 0.21 & 1.35 & 0.14 \\
\hline & $(40-49)$ yrs. & 1.48 & 0.13 & 1.35 & 0.12 \\
\hline \multirow{5}{*}{ Hand } & ( 7-13) yrs. & 0.65 & 0.11 & 0.61 & 0.08 \\
\hline & (14-19) yrs. & 0.69 & 0.09 & 0.63 & 0.13 \\
\hline & (20-29) yrs. & 0.61 & 0.07 & 0.58 & 0.07 \\
\hline & $(30-39)$ yrs. & 0.63 & 0.06 & 0.56 & 0.12 \\
\hline & (40-49) yrs. & 0.63 & 0.05 & 0.63 & 0.12 \\
\hline
\end{tabular}

Table B 6 Centers of masses (unit: \%)

\begin{tabular}{|c|c|c|c|c|c|}
\hline \multirow{2}{*}{\multicolumn{2}{|c|}{ Segment / Group }} & \multicolumn{2}{|c|}{ Male } & \multicolumn{2}{|c|}{ Female } \\
\hline & & mean & S.D & mean & S.D \\
\hline \multirow{5}{*}{$\begin{array}{l}\text { Foot + Shank } \\
+ \text { Thigh }\end{array}$} & ( 7-13) yrs. & $45.3^{*}$ & 0.08 & 48.6 & 0.18 \\
\hline & (14-19) yrs. & 51.7 & 0.09 & 45.9 & 0.08 \\
\hline & $(20-29)$ yrs. & 47.7 & 0.09 & 42.7 & 0.09 \\
\hline & $(30-39)$ yrs. & 43.1 & 0.11 & 41.9 & 0.10 \\
\hline & (40-49) yrs. & 44.7 & 0.09 & 43.7 & 0.09 \\
\hline \multirow{5}{*}{ Foot + Shank } & ( 7-13) yrs. & 46.2 & 0.09 & 50.6 & 0.11 \\
\hline & (14-19) yrs. & 51.8 & 0.06 & 48.9 & 0.09 \\
\hline & $(20-29)$ yrs. & 50.9 & 0.09 & 44.8 & 0.11 \\
\hline & $(30-39)$ yrs. & 44.2 & 0.12 & 45.1 & 0.11 \\
\hline & (40-49) yrs. & 46.2 & 0.09 & 46.6 & 0.19 \\
\hline \multirow{5}{*}{$\begin{array}{l}\text { Hand + Forearm } \\
\text { + Upper arm }\end{array}$} & ( 7-13) yrs. & 48.3 & 0.11 & 48.2 & 0.12 \\
\hline & (14-19) yrs. & 41.9 & 0.08 & 43.1 & 0.09 \\
\hline & $(20-29)$ yrs. & 40.2 & 0.08 & 39.0 & 0.07 \\
\hline & $(30-39)$ yrs. & 42.8 & 0.07 & 40.4 & 0.09 \\
\hline & $(40-49)$ yrs. & 45.6 & 0.08 & 45.3 & 0.11 \\
\hline \multirow{5}{*}{ Hand + Forearm } & ( 7-13) yrs. & 50.6 & 0.11 & 50.6 & 0.13 \\
\hline & (14-19) yrs. & 43.9 & 0.08 & 38.8 & 0.13 \\
\hline & $(20-29)$ yrs. & 42.7 & 0.09 & 41.5 & 0.08 \\
\hline & (30-39) yrs. & 45.6 & 0.08 & 42.4 & 0.09 \\
\hline & (40-49) yrs. & 47.3 & 0.08 & 47.3 & 0.12 \\
\hline
\end{tabular}

*percentage from proximal end. 


\section{References}

Ackland TR, Henson PW, Bailey DA (1988) The uniform density assumption: its effect upon the estimation of body segment inertial parameters. International J ournal of Sports Biomechanics 4: 146-155

Brooks CB, J acobs AM ( 1975) The gamma mass scanning technique for inertial anthropometric measurement. Medicine and Science in Sports and Exercise 7: 290294

Chandler RF, Clauser CE, McConville JT, Reynolds HM, Young JW (1975) Investigation of inertial properties of the human body. DOT HS-801430. Wright-Patterson Air Force Base, $\mathrm{OH}$

Clauser CE, McConville JT, Young J W (1969) Weight, volume, and center of mass of segments of the human body. AMRL-TR-69-70. Wright-Patterson Air Force Base, $\mathrm{OH}$

Dempster WT (1955) Space requirements of the seated operator. WADCTR-55-159, Wright-Patterson Air Force Base, $\mathrm{OH}$

Drillis R, Contini R (1966) Body segment parameters. DHEW 1166-03. New York University, School of Engineering and Science, New York

Hanavan EP (1964) A mathematical model of the human body. AMRL-TR-64-102, Wright-Patterson Air Force Base, $\mathrm{OH}$

Huang HK, Suarez FR ( 1983) E valuation of cross sectional geometry and mass density distributions of humans and laboratory animals using computerizered tomography. J ournal of Biomechanics 16: 821-832

Huang HK, Wu SC (1976) The evaluation of mass densities of human body in vivo from CT scans. Computers in Biology and Medicine 6: 337-343

Jensen RK (1978) Estimation of the biomechanical properties of three body types using a photogrammetric method. Journal of Biomechanics 11: 349-358

Kaleps I, Clauser CE, Young J W, Chandler RF, Zehner GF, McConville J T (1984) Investigation into the mass distribution properties of the human body and its segments. Ergonomics 27: 1225-1237

Kim DJ, Lee YS, Kim, SC, Yang HS, Lee, KS (1997) National anthropometric survey of Korea. KRISS-97114-IR

Lim H, Lee Y, Kim CJ, Lee NS, Park SJ (1993) Body segment's mass, center of mass and moment of inertia of Korean. Proceedings of the KSME Autumn Annual Meeting: 15-19

Martin PE, Mungiole M, Marzke MW, Longhill J M (1989) The use of magnetic resonance imaging for measuring segment inertial properties. J ournal of Biomechanics 22: 367-376

Mungiole M, Martin PE (1990) Estimating segment inertial properties: Comparison of magnetic resonance imaging with existing methods. J ournal of Biomechanics 23 : 1039-1046

Nakanishi Y, Nethery V (1999) Anthropometric comparison between J apanese and Caucasian American male university students. Applied Human Science 18: 9-11

Rodrigue D, Gagnon M (1983) The evaluation of forearm density with axial tomography. J ournal of Biomechanics 16: 907-913

Winter DA (1979) Biomechanics of Human Movement. John Wiley \& Sons, New York

Received: J anuary 12, 1998

Accepted: March 19, 1999

Correspondence to: Se J in Park, Ergonomics Research Group Korea Research Institute of Standards and Science, Daedeok Science Town, Daejon, Korea, 305-600 